\title{
The Estimate and Selection of the Informatics Resources of Fulfiling of the Evolution of Economic Situational Information
}

\author{
Tudor Ştefan LEAHU \\ Co-operative Trade University, \\ Chişinău, Republic of Moldova \\ leahu.ts@mail.ru
}

The created situation, the factors, what contributing at it, is characterized. The necessity of return and revision of elaborative stage of constitution of the economic informatics systems (E.Ic.S.) it's substantiated. Also, the idea of opposite order of the concept of invention, elaboration, production and application of the informatics resources, as well as, and the concept of them estimation and selection are formulated.

Keywords: Estimate, Selection, Informatics Resources, Conceptual Criteria

1

Introduction

In conditions of the approach completely informational society, except the problems of the invention, production and using the informatics means and technological methods in any sphere of the human activities, of decisive importance disposing the rational selection, what directly affecting the working of the E.Ic.S.

That is why, off the scientificaly positions and economical raison, alwais itself soliciting the works, which precede herself the projection and implementation of these systems, as the establishing of the composition and elaboration of the criteria of selection of informatics resources.

\section{Content}

\section{A. The fundamental thesis $[1,283$-286]}

It is well known what today and in predictable perspective the rational organization and efficient working of unitary economic informational process are conditioned of through application of the advanced informatics means and methods in the named sphere. Also, its awared what the systemic (in interconnection and interaction) approach and achievement of these two components (means and methods) are finded your accomplishment in the shape of economic informatics systems (E.I.. S.).

In one's turn, for to evolve, apart these two, the latters soliciting the implication into and other resources. Among them of vital functional importance are those informational,

mathematical, programmatical, economical, ergonomical and social-juridical. From the scientific point of view, without connecting of all these components into a single chain, both on the elaborative, as well as the functional stage not may be achivied the E.I.S.S. Another modality of interpretation and perception of such systems not ensuring them hypothetical performance and, therefore, of the informational system of leaded object, and finally - of the managerial system.

Depending of the level of leadership, such systems, especially those of higher order, disposing of the very much diverse composition and the excessive volumes of information and the works. These parameters, one the one hand, and the objective constraint of the systemic approach, on the other hand, all more to contributing to be awared the need to effect a one complexe of preparatory works of projection content, or, rather, to return to them, very much as, at the same time with the massive implementation of electronic personal computers (E.P.C.), from more objective and subjective motives, practical entirely have been almost forgotten.

As a motivation of justification of created situation, as a rule, himself advanced such arguments, how are the directly physical acces of the user at the informatics technical means, in first hand, at the computer, them relatively cheap cost, "simplified" of the procedures of programming, because that 
them becoming more "friendly", the progressive "reduction" of informatics technologies at the manual (according to content, composition and succession of them realization, but not and according to the modality them execution), a.s.o.

The necessity to return and review the elaborative stage of the E. Ic. S. is based not only on the scientific awareness of them establishment and functioning, but on the household raison. In composition of this stage of the decisive paramount importance it's the selection of informatics components, which, in fact, precede herself the projection of this category systems.

If as such the projection, unconsciously and undocumented, more on the very relatively level, conceptually unfounded, sometimes is intuitively achieved only about the technical component (P.C.), then selection of the other basic resources E. Ic. S. was, is and does not know how long time it will be neglected. The reality of the scientific and economic conceptions, early or later, after all will imposing the effectuation of the works of this decisive important stage, very much as the results of the selection forming the basis of the correctly starting, continuation and completion of the elaboration and of implementation, as well as and assurance rational organization, efficient and adequate working of the E. Ic. S. in accordance with the objective informational environnment.

The thrifty attitude given of the sizes of expenditures coherently with the creation and exploitation of E.Ic.S. It's indicated especially for the existing economic informational medium, that is characterized by fragmented informatics covering, complex variety of the informatics means and methods, the lasts to being explaining for the same neglect of the systemic approach of achievement of the sphere in cause.

Following further on such motivation, it may be establish that the conception of the invention, elaboration, production and application of informatics means and methods require the inversion of the orientation comparatively with the existing outlook. All the more so at that contributing the technical-scientific progress and discoveries of fundamental sciences (physics, chemistry, biology, a.s.o.).

The essence of this inversion itself reducing to the fact that the technical means and technological methods must having elaborated and implemented in basis of the qualitative (composition, structure) and quantitative (volume of activities, information, etc.) parameters of the sphere of them application. Until, firstly itself inventing and elaborating some or other means and respectively methods and only after this itself studing and discovering the possibilities for them application in concrete area. Therefore, the informatics achievement of the informational processes must to being started and oriented not from the means and methods to domain, but on the contrary: from the domain - to the means and methods.

As to rationally thrifty aspect of the selection, is established that it's necessary taking into account of it in any situation, independently of degree of facility of the employement of the means and methods and them reduced cost. However much simple not would be them application and however not would much cheap them, from the economic point of view, are inadmissible the moreover expenditures, as of small not would may be them, especially in the environment of the relation of the market economy. Apart this, the founded selection of the informatics resources adequated of the information relations, contributing also at the extension of the terms of working of the informatics components, as well as within the framework it's taken into consideration not only the existent situation, but and the perspective of evolution of the informatives and decisionales activities. Consequently - and the use, not only physically, but and morally, not present so pronounced risk, as in cases when such selection is not carring out.

The mentioned factors and many others circumstances indicate firstly at the determination of the basic informatics components, without what not perhaps daily efficient working the E. Ic. S., that is necessary to be selected for to create such 
system, the principles and criteria of selection them. After as was mentioned from beginning, the main components of E. Ic. S. are considered technical, informational, mathematical, programmed, technological, economical, ergonomical and socio-juridical resources.

The enumeration of these resources is based on the principle of motivation, because the technical means, having of the certain parameters and operating characteristics, practically predetermine the composition and volumes (number) of other components. At the same time, from the standpoint of the selection, it is necessary to starting to the informational resources, with all those valences.

This taking place since only having of composition and volumes of information, of works executed above them and the sizes of the time periods of execution of latters, with the aid of the calculation methods can be determined, more or less, with exactness, what technical means, in how number, with what functional characteristics, are necessary for to bring into operation and to ensure the daily efficient working, on the long period of concrete informatics system.

If until now in the informatics practice almost no made such calculations, but in theory them themselves referring prevalent of computing technique, today, then more and more obviously and urgency becoming the problem of the complete covering of the entirely informational cycle of the technical means. In a such situation arising the problem of selection not only the technical means of data processing (computers), but also and those means, which executing others procedures and technological operations of the unitary informational process.

In outline the selection of any resources, which ensuring the working of the E.Ic.S., require the detailed knowledge of the composition of them operating "posibilities", also of the parameters and characteristics of the applied domain, the criteria of the selection of the informatics components through comparaison of the "abilities" of letters with the specifical requirements of the real administrative system.

Finaly, it's necessary attentioned above of the fait that the nelecting of practice and theory of selection of the informatics resources negative influenced the quality of the working of economic informational systems, which can not to be affected and on the results of the human material activities and in environment of market relations - and above the level of the social prosperity. Therefore, in current situation it importance it's of the primordial order and all growing vital value.

In accordance with the previously confirmation, the strategy of the selection of these resources and, especially, a those tehnical, is based on determination of them composition and volume (number) to starting from qualitative and quantitative parameters of the information entities and processes. Therefore, the essence of this strategy to come to those what the informatics technical means and technological methods must to being elaborated and implemented in accordance with the characteristics of qualitative (composition, structure) and quantitative (volume of information, works a.s.o.) parameters of the domaine them applied. Until, however, firstly itself invent some or other means and technologies, and only after this itself examined and highlighting the opportunities of them aplication in the concrete domaine. Thus, both the existing situation and for the future, the primordial strategy of the informatics achievement of economic informational processes needed to be reoriented, the latter consisting in that the informatics modality of achievement of informational activities must itself being started and directed dont from the means and methods to the them applied area, but conversely - from this domain to means and methods it needed.

During of the selection of the in cause means is necessary to take into account and the conception of the informatics technique evolution, that may by of the following two variations: 
1) invention and application how many one technical mean for each technological action or operation;

2) creation and utilization of such technical mean or aggreagate mean, that will to fullfiling all actions and operations of the unitary techological process.

For the first of them, which now prevails, one of the most pressing issues that permanently must bear in sight and solved, is ensure of the compatibility of working of the such means chain during of the realization of unitary informational process in milieu of the economic unit, each subdivision and participant (resource) of them.

That is why, in the event of creation of each technical mean fated for effectuation one work (action, operation), is necessary to take into account the possibilities of it physical coupling, the productivity of working of such technical means chain, of interactions between them. The last (unitary rhithm) itself reducing to that what in the process of selection of diverse variety of technical means of achievement of the various works, it's necessary to be guided by the such concept of decisive essence, as is that of compatibility, what is based on the following three basic principles of inter correlative order:

1) the functional intercorrelation principle, the meaning that itself reducing to that what any technical mean involved in the unitary informational process must have of functional capabilities to ,prolong” working of this previous technical mean, to achieve one's him function (action, operation), and after that - to ,transmit” (to initiate, to incite) the function of next technical mean what fullfiled the following work (action, operation). If the succedente technical mean finished the informational process, then, in all cases, it must not only achieved its own work, but and to offered the respectively final product through its concluding in the most convient manner for the end user;

2) the technical intercorrelation principle, what consists in determination of the constructive structure in such way as any mean of such variety to have the posibilities of phisical coupling with any other mean, which achieving the previous and succedente works what are achieving of selected technical means. Othervise being statement, a such mean constructive it have created in the mode, which ensuring the functional connection with other means, both being it physical inputs and outputs.

It's necessary to take into account and that fact what if the technical mean initiating the unitary informational process (itself finded at the beginning of the chain of technical means (functional interconnected complex), then, obviously, what to the entries must so that having the possibilities of physical coupling with the material source (object, operation) of extraction of the initial (primary) data. Also, the technical means must let ensuring the automatic transformation of units of the material measurement in the informational units. This requiring so that taking place firstly compositional (to be praising and to recognized (indentify) them composition), but after-quantitative (volume, them number);

3)the productive intercorrelation principle (temporary, of speed of physical functioning). Thus principle is based on the ensurance of a such functioning of the informatics technical means that the speed of some of them will not to stoping the functioning of subsequent technical means of the unitary chain and, also, and this technical mean so that not be in waiting of the end of functioning of the precedent technical means, which its provide with the "processing material'" (initial data).

The general speed of working of the chain of technical means what itself accomplishing the unitary informational process, in his turn, must so that be correspondingled with the speed of working of the leded material object (process) and speed of the response of it management system.

In the variant, when some or all procedures and operations of unitary informational process are achivied by a single technical mean, it is necessary that the latest to fulfilled in automatically mode, without involving of the subject in it working, 
leaving in prerogative of the latter only the operations of the introduction in functioning, the stoping of functioning and following of the adequatetation of functioning of technical means, in accordance with the initially determined algorithm. Therefore, such mean it's nothing something else than the physical (biological, chemical, a.s.o.) model of the process of automatically solving of a problem or a complex of problems.

At the moment, however, and in predictable prospect, also, is difficult to suppose that the technical mean, which integral would achieve the economic informational process, will be created and put into functioning. On a general plan the created situation it explained by the specific of domain and the level of evolution of the naturally and applicative sciences. Regarding the first factor, here are evidently such characteristics of it as the pronounced dynamics both compositional and structural and dimensional.

From this cause not it successful and, probably, will never is not fully succeed integral with the informatics achievement of the informational economic activities.

The second factor one referring of existing situation of the low level of informatics technical and technological discoveries, inventions and performances what dont contributing to the ihtegral covering of the economic informational field. Not are negligible and so particularities of the economic material processes, as to the pronounced varying of the dynamics, functioning of the informational resources, is a need to determine them composition and volumes. For to select the technical resources preliminary himself requiring to determine the gamma of the such means, them explotative characterics and functional "capacities", phisical and techlogical compatibility, a.s.o.

So as, the palette of the methods and proceedings of existence and transformation of the economic situational information is pronounced varied and numerous, itself entailing the clearing up particulary each of them, in concordance to the succession of composed composition, considerable size of spacial and temporary rays of making them. Identically and the informational process, being incidents from the material and always accompanied them, to have the some characteristics.

According to the principle of determining of the composition and volumes of informatics resources, to starting from the values of qualitative and quantitative parameters of the informational domain, as well as on the base of certain accumulated experience and till now formulated scientific thesis, is justified the next succesion of the selection of mentioned resources:

1) the selection of the methods of the organization, structuration and working of economic informational resources;

2) the selection of the technical resources;

3 ) the selection of the mathematical and programmed resources;

4) the selection of the organizational and technical resources;

5) the selection of the social-economic resources.

The compositional ordre and the succession of the effectuation of enumerated works not exclude the returns to the initial stages from to those already effecteds, because them are finding in the urgent interdependence, some being conditioned on other.

Moreover, for to be accomplished, the selection require the same preparatory works. So, for example, for to select the methods of the organizing, structuring and conception of them elaboration and functioning.

\section{B. The Selection of the Methods and Ways of the Organizing of Economic Situational Information [1,47-96; 2,135-193,285-306;5, $100-135 ; 6,33-47,135-162]$.}

At once, those most elaborated, more conceptually and unusual achieved in informatics practice, are methods of organization data on the physical space of computer memory. Such situation oneself explained of the circumstances of need of to keeping of data values which are required by the particularities of economic informational 
problems. So, in dependence of the physical environment of the computer memory, all the methods of the physical packing of data can be systematized into two groups - the methods one's own for physical space of the operative (internal) memory and the methods own for the milieu of the external memory. Taking in consideration the fact that the packing of data on the operative memory (O.M.) not can be achieved without of the organization of certain areas in the external memory (E.M.), itself requiring the necessity to establishing the interconnections and interactions between of the both groups of above mentioned methods. Moreover, herself taking into account not only the functional compatibility, but also the posibilities of these interdependences, regarding the ensurance of promptness of data manipulation in base of the concordant joing of the in cause methods.

Starting from the cleared up resons, the possible interconnection and interaction between the physical methods of data packing on the space of the internal and external millieu of computer memory are presented in table $1[1,286-292 ; 6,150-162]$.

The presented in this table concordance between the methods and physical proceedings of data packing on the O.M. and E.M. spaces are more efficacious in cause of correctly selection of data structures for any informational entity of the respective problem.

On the basis of the particularities of transformation of functional economic informational entities, on the conceptual level was determined the orientative composition of the data structures indicated for the any group of the problems of economic management undersystem and presented in the table 2 .

[1,290-292; 6,153-154]

\section{The Estimation and Selection of Economic Situational Data Structures \\ [1,129-148;2,56-65;6,150-154]}

Are known many criteria of estimation of data economic structures, on the basis of which tacking place them selection, however, fundamental itself though the nexts:

1) the promptness of forming (systematization, sorting, arranging) of the data structures;

2) the rational (thrifty) level of utilization of memory space ;

3) the comform and promptness of the correction of data structure

4) the promptness of the recovering of the structural elements ;

5) the general criterion $[1 ; 6]$.

Table 1. The interconnections and interactions of proceedings of the data physical packing on the operative memory (O.M.) and external memory (E.M.), depending of the type of data structures (D.S.) $\left.{ }^{*}\right)$

\begin{tabular}{|c|c|c|c|c|c|c|}
\hline \multirow{4}{*}{$\begin{array}{l}\mathrm{NN} \\
\text { ord }\end{array}$} & \multirow{4}{*}{$\begin{array}{c}\text { Type of the data } \\
\text { structures }\end{array}$} & \multicolumn{5}{|c|}{ Physical packing proceedings } \\
\hline & & \multicolumn{3}{|c|}{ On operative memory (O.M.) } & \multicolumn{2}{|c|}{ On external memory (E.M.) } \\
\hline & & \multirow{2}{*}{$\begin{array}{l}\text { The } \\
\text { method }\end{array}$} & \multicolumn{2}{|c|}{ Organized areas } & \multirow{2}{*}{$\begin{array}{c}\text { The } \\
\text { method }\end{array}$} & \multirow{2}{*}{ Organized areas } \\
\hline & & & on O.M. & on E.M. & & \\
\hline 1 & $\begin{array}{c}\text { The succesive } \\
\text { data structures - } \\
\text { S.D.S. }\end{array}$ & $\mathrm{S}$ & - & R.A. & $S$ & D.A. \\
\hline \multirow[b]{2}{*}{2} & \multirow{2}{*}{$\begin{array}{c}\text { The row data } \\
\text { structures - } \\
\text { R.D.S. }\end{array}$} & \multirow{2}{*}{$\mathrm{C}$} & \multirow{2}{*}{ L.A. } & \multirow{2}{*}{ R.A. } & $S$ & D.A. \\
\hline & & & & & D & D.A. \\
\hline \multirow{2}{*}{3} & \multirow{2}{*}{$\begin{array}{c}\text { The compound } \\
\text { data list } \\
\text { structures - } \\
\text { C.D.L.S. }\end{array}$} & \multirow{2}{*}{$\mathrm{N}$} & \multirow{2}{*}{ L.A. } & \multirow{2}{*}{ R.A. } & I.S. & D.A. \\
\hline & & & & & $\mathrm{R}$. & I.A., D.A.,O.A. \\
\hline
\end{tabular}




\begin{tabular}{|c|c|c|c|c|c|c|}
\hline & & & & & S & D.A. \\
\hline \multirow{6}{*}{4} & \multirow{6}{*}{$\begin{array}{l}\text { The tabular } \\
\text { (matrixly) data } \\
\text { structures - } \\
\text { T.(M.)D.S. }\end{array}$} & \multirow{2}{*}{ B.R.Z. } & \multirow{2}{*}{ A.T.C. } & \multirow{2}{*}{$\begin{array}{c}\text { A.O.V.,A.O.C., } \\
\text { A.K.R. }\end{array}$} & $S$ & D.A. \\
\hline & & & & & I.S. & R.A.,D.A.,O.A. \\
\hline & & \multirow{2}{*}{ L.P. } & \multirow{2}{*}{ L.P.A. } & \multirow{2}{*}{$\begin{array}{c}\text { A.O.V.,A.O.C., } \\
\text { A.K.R. } \\
\end{array}$} & $S$ & D.A. \\
\hline & & & & & I.S. & I.A.,D.A.,O.A. \\
\hline & & \multirow{2}{*}{ C.I. } & \multirow{2}{*}{ A.C.I. } & \multirow{2}{*}{$\begin{array}{c}\text { O.V.A., O.C.A. } \\
\text { K.R.A. }\end{array}$} & S & D.A. \\
\hline & & & & & I.S & I.A.,D.A.,O.A. \\
\hline \multirow{2}{*}{5} & \multirow{2}{*}{$\begin{array}{c}\text { The arborescent } \\
\text { data structures - } \\
\text { A.D.S. }\end{array}$} & S.(D.)A. & $\begin{array}{c}\text { L.A. } \\
\text { (R.A.A.) }\end{array}$ & R.A. (E.A) & I.S. & I.A.,D.A.,O.A.. \\
\hline & & T.N. & $\begin{array}{c}\text { L.A. } \\
\text { (N.E.A.) }\end{array}$ & R.A. (E.A.) & I.S. & I.A.,D.A.,O.A.. \\
\hline
\end{tabular}

*) The organized areas:

a) on the O.M. space : L.A. - the list area, I.D.A. - the indicators area, A.T.C. - the area of the table of concordance, L.P.A. - the logical plate area, A.C.I. - the area of the couples of the indexis, R.(D.)A.A. - the relation (dart) addresses of area, N.E.A. - the area of element numbers;

b) on the E.M. space: R.A. - the recordings area, O.V.A. - the objects vectors area, O.C.A. - the object characteristics area, K.R.A. - the keeping rows area, E.A. - the elements area, D.A. - the data area, I.A. - the indexis area, R.A. - the references area (the relation adress of D.A.), D.C.A. - data collections area, D.A. - the outrunning area,T.N. - " trace notation", R.A.A.relation addresses of area. The methods of the physical packing of data: on O.M. space : $\mathrm{S}$ - succesiv, $\mathrm{L}$ - in chain, $\mathrm{N}$ - in nest, $\mathrm{K}$ - in knot, B.R.Z. - the basic and reserve zone, L.P. - logical plate, C.I.couples of addresses; on E.M.: I.S.- indexedsuccessive, O.A.- objects area.

The enumerated criteria are caracterized by certain values, which are calculated in accordance with the respectively formula [1, 290-300; 6, 170 - 175].

Table 2. The conceptual selection of the data structures convients for the informational entities of the any group of problems of economic management undersystems.

\begin{tabular}{|c|c|c|c|}
\hline $\begin{array}{l}\text { Undersystem of } \\
\text { economic } \\
\text { management }\end{array}$ & $\begin{array}{l}\text { The group of the } \\
\text { problems of undersystem } \\
\text { of economic management }\end{array}$ & $\begin{array}{l}\text { The categories of involved } \\
\text { information in the solving } \\
\text { group of problems }\end{array}$ & $\begin{array}{l}\text { The data } \\
\text { structures } \\
\text { selected for } \\
\text { informatics } \\
\text { organization of } \\
\text { categories of } \\
\text { the } \\
\text { information }\end{array}$ \\
\hline \multirow{3}{*}{$\begin{array}{l}\text { The rate-settings } \\
\text { and regulation of } \\
\text { the economic } \\
\text { material } \\
\text { activities } \\
\text { (R.S.E.M.A.) }\end{array}$} & $\begin{array}{l}\text { The calculation of the } \\
\text { values of primary rates }\end{array}$ & Primary measurement data & $\begin{array}{l}\text { The succesive } \\
\text { data structures }\end{array}$ \\
\hline & $\begin{array}{l}\text { The calculation of the } \\
\text { applicabilities }\end{array}$ & The rates of applicabilities & $\begin{array}{l}\text { The } \\
\text { arborescent, } \\
\text { reticular data } \\
\text { structures }\end{array}$ \\
\hline & $\begin{array}{l}\text { The calculation of the } \\
\text { values of general rates }\end{array}$ & The primary rates & $\begin{array}{l}\text { The } \\
\text { arborescent, } \\
\text { reticular data } \\
\text { structures }\end{array}$ \\
\hline forecast & The calculation of the & All categories of & reticular \\
\hline
\end{tabular}




\begin{tabular}{|c|c|c|c|}
\hline $\begin{array}{l}\text { (F.P.) } \\
\text { current } \\
\text { foreseeing } \\
\text { planning } \\
\text { (C.P.) }\end{array}$ & $\begin{array}{l}\text { values of forecast } \\
\text { foreseeing indicators of } \\
\text { the evolution of economic } \\
\text { material activities. } \\
\text { The calculation of the } \\
\text { values of indicators of } \\
\text { another compartments of } \\
\text { current planning }\end{array}$ & $\begin{array}{l}\text { technical, economic, social } \\
\text { information. } \\
\text { The financial admini- } \\
\text { strative (account } \\
\text { statement) data, the values } \\
\text { of the current planning, } \\
\text { economic analysis and } \\
\text { rate-setting indicators }\end{array}$ & $\begin{array}{l}\text { data structures } \\
\text { The compound } \\
\text { data list } \\
\text { structures } \\
\text { The reticular } \\
\text { data structures } \\
\text { The compound } \\
\text { data list } \\
\text { structures }\end{array}$ \\
\hline $\begin{array}{l}\text { The operative } \\
\text { planning and } \\
\text { directing of } \\
\text { economic } \\
\text { material } \\
\text { activities } \\
\text { (O.P.D.E.M.A.) }\end{array}$ & $\begin{array}{l}\text { The calculation of the } \\
\text { values of indicators of } \\
\text { operative planning of } \\
\text { evolution of economic } \\
\text { material activities. } \\
\text { The calculation of the } \\
\text { values of indicators of } \\
\text { another compartments of } \\
\text { operative planning }\end{array}$ & 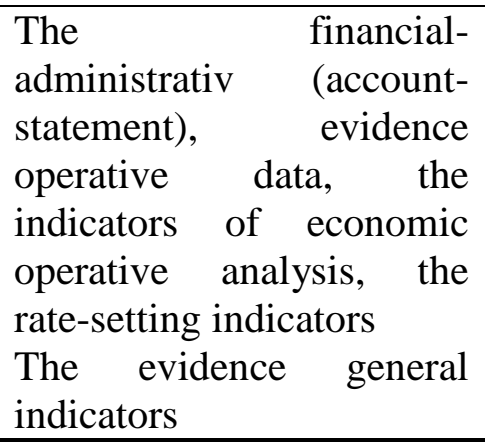 & $\begin{array}{l}\text { The compound } \\
\text { data list } \\
\text { structures } \\
\text { The reticular } \\
\text { data structures }\end{array}$ \\
\hline $\begin{array}{l}\text { The evidence } \\
\text { and financial } \\
\text { administration } \\
\text { (E.F.A.) }\end{array}$ & $\begin{array}{l}\text { The problems of } \\
\text { operative evidence. } \\
\text { The problems of book- } \\
\text { keeping. } \\
\text { The problems of the } \\
\text { financial administration } \\
\text { (account) }\end{array}$ & $\begin{array}{l}\text { The evidence general } \\
\text { indicators. } \\
\text { The indicators of } \\
\text { estimation and hauling } \\
\text { time of the economic } \\
\text { resources. } \\
\text { The indicators of account } \\
\text { (financial administration) }\end{array}$ & $\begin{array}{l}\text { The successive } \\
\text { data structures. } \\
\text { The } \\
\text { arborescent, } \\
\text { tabular } \\
\text { (matrixly) data } \\
\text { structures }\end{array}$ \\
\hline
\end{tabular}

The estimation of any data structure on the basis only of one at the essential enumerated criteria is unilateral, and therefore, erroneus, because each criterion characterizing such structure in accordance with the value exclusively of one them parameter. Moreover, some criteria are unaccepatable for any data structures. That is why with a view to generalizing them values can be applied the synthesizer of weighing, assignement of concrete values for them is enough dificult, if not impossible. So started from the principle that any of the criteria is not we given priority, assigning each a special parameter - points.

The calculus of the size of this parameter is bazed on the concept, in concordance with the value of the criterion is all the diminished as, the structure is more it's concordant. If some structures have the equal values of one and the same criteria, then all are assigned the equal points. For other structures such value may be determinated through comparing of those values with the value of the comparable structure. Through the addition of the every peculiar values to obtain the generalizing value of the structure [1,302-303].

The results of the estimation of data structures on the basis of generalizing criterion may be concluding under of table 3 . The generalizing estimation of the data structures can tacking place and through comparing of the couples of such structures on the basis of calculation of values of two criteria. 
Table 3. The example of the generalizing criteria of estimation of the data structure

\begin{tabular}{|l|l|l|l|l|l|c|}
\hline \multirow{2}{*}{$\begin{array}{l}\text { NN } \\
\text { ord }\end{array}$} & \multicolumn{1}{|c|}{$\begin{array}{l}\text { The varietes of } \\
\text { data structures }\end{array}$} & \multicolumn{4}{|c|}{ The criteria of the estimation } & \multirow{2}{*}{$\begin{array}{c}\text { The sum } \\
\text { of the } \\
\text { points }\end{array}$} \\
\cline { 3 - 6 } & & $\begin{array}{l}\text { Time of } \\
\text { formation } \\
\text { (sorting) }\end{array}$ & $\begin{array}{l}\text { The } \\
\text { supplimentary } \\
\text { space of } \\
\text { memory }\end{array}$ & $\begin{array}{l}\text { Time of } \\
\text { recoveri } \\
\text { ng }\end{array}$ & $\begin{array}{l}\text { Time of } \\
\text { correction }\end{array}$ & \\
\hline 1 & $\begin{array}{l}\text { Succesive } \\
\text { structure }\end{array}$ & 2,5 & 1 & 1 & 13 & 17,5 \\
\hline 2 & $\begin{array}{l}\text { In succesion one- } \\
\text { directional data } \\
\text { structure }\end{array}$ & 2,5 & 4 & 8,5 & 7,5 & 22,5 \\
\hline 3 & $\begin{array}{l}\text { In succesion two- } \\
\text { directional data } \\
\text { structure }\end{array}$ & 5 & 5 & 8,5 & 9 & 27,5 \\
\hline
\end{tabular}

The calculation of the values of estimation criteria of the data structures for them further organization and informational or structural processing is need tacking place after «junction » of functional organizing of the informational entities with the possible variants of informatics them organization and processing. Therefore, the determination of the variety of data structure, which is concordant with concrete informational entity is necessary to effectuated in following succession:

1) the determination of the composition of the functional informational entities, of them structures, methods of organization and transformative procedures proper them ;

2) the selection for them informatics achievement of possible data structure, proceedings (methods) of physical packing on the espace of the opertaive and external memories, as well as of respectively informatics transformational procedures ;

3 ) the calculation of the estimation criteria of data structure, them physical methods of packing and transformation procedures already selected (at the second stage).

D. The Presentation, Estimation and Selection of Transformation of the Values of Situational Economic Data [1,129. $148 ; 2,56-65 ; 6,150-154]$.

At present for the examination and understooding of processing process exercized concerning data values oneself applieding various algorithms, which after forme of the presentation are systematized in such three essential groups - oral (textual), mathematics (under forme of formula) and graphics (under forme of various schemes). At the moment, the last group is on of the most developped and in combination with mathematical methods of formalizing in the most detalied and clearly mod presents the logical sequence of solving problems. The most spreads ways of graphical describing of processes of the solving of economic informative problems found them realization in the form of block diagram, diagram of programmed lines and scheme of the operators. Still are known and applied the modul schemes and informationaltechnological schemes. After volume of the presentation of in cause processes, the last cathegorie of such schemes (of operators) is one of the most economical, but they can help determine on the general level only the scheme of the succesion of achievement of procedures and operations data processing, which is insufficient for that goal.

Very much as initially the informatics technique prevalent achievementing the calculation processing, in graphically shape itself presenting only this cathegory of operations. At present the technique automatic fullfilling the informational and structural processing, in examination 
schemes them are comprised incompletly and fragmentally, that more through are presented in informational-technological schemes. But, and here not are presented the mathematical algorithms,its being replacing of the certain programme moduls, what creating obstacles in the revealing of calculable content of problem, of going and succession of it solving stages. From his raison, such schemes resemble more with informational models of solving of the informativ content problems. Therefore, such cathegory of schemes solicit the perfecting, which himself reduced to them completion with all necessary of calcul and incalcul procedures data processing, as well as with respectively identifiers of the informational units.

The estimation of the processing procedures and operations of information depending on the modalities of them achievement and of the goals of this estimation, which consist in determination and selection the composition of the informatics technical resources and the identification of the data transformative works. But, in created situation not always himself following the principal - obtaining of qualitative informational products.

In such cause the criteria of estimation of the transformative procedures and operations perhaps expressed in values of the indicators of quality of informational products. At the same time, the limitation of the estimation with such indicators is unilateral. That is why is necessary again to applied and the quantitative estimation criteria, the which values are expressed in number of procedures, operations, instructions a.s.o., what reverting at a informational unit $[1,304$ - 306 ; 2, 93-132 ;6, 94-106].

\section{E. The Selection of the Informatics} Technical Resources $[1,306-325 ; 3,56-59$; 4, 73- 76].

The selection on the scientific basis of the informatics technical means demanding supplementary the effectuation of a row of preparatory works of preliminary order.

After content and the order of achievement such works can being dividing in nexts two stages:

1) the sistematization (grouping) of the having informatics technical means on the basis of the certain criteria of them classification and of the material sources of information ;

2) the determination of the necessary composition of exploiteds parameters and characteristics of excellent worker (existents) informatics technical means, on the basis of which and herself effecting them selection.

At the first stage itself imposing the next's preparatory works in the following succesion:

1) the determination of the composition and the number of the material (physical) sources of the information (activities, processes, operations, objects and resources involved in them working) with the respectively systematization orientated (dictate, imposed) of the goals of selection of the technical means ;

2) the making evident and grouping of the having (existents at the moment) informatics technical means on the basis of the criteria of them maximum through, of composition and characteristics of the material sources of information ;

3) the determination of the composition of necessary functional parameters for effectuat ion the selection of the technical means and of them exploatative characteristics.

At the scientific view point, only after effecting these complexes of works, enough of complicate and sizable can be to initiate the selection of the informatics technical means. But, befor this itself determining the categories of this means and in the interior of each of them are establishthing principles and criteria of selection. The existent level of the evolution of informatics technique to permite the making evident the followings essential classes of they:

1) technical means for extracting, recording and transmission of the primary information ;

2) technical means of multiplication (copying) of information values ;

3) technical means of data exchange and transmission of them at the distance ; 
4) technical means for processing and concluding (documentation) of information. The first group of the technical means more oneself consider the means of the data primary. The composition and the succession of effecting of the works of the stages of the selection of this means is presented in fig. 1[1, $306-312]$.

Regards the technical means of the groups 23 , them selection itself effecting on the base of the informational volume what's necessary proceeding and the size of the time period allocated in this goal [1, 313-325]. That's way the general formula of calculation of the speed of them functioning is showing in following mode :

$$
S_{f}=I_{v}: T_{p} ; \quad \text { where }:(1)
$$

$S_{f}$ - speed of functioning, $I_{v}$ - invormational volume, $T_{p}-$ the size of the temporary period.
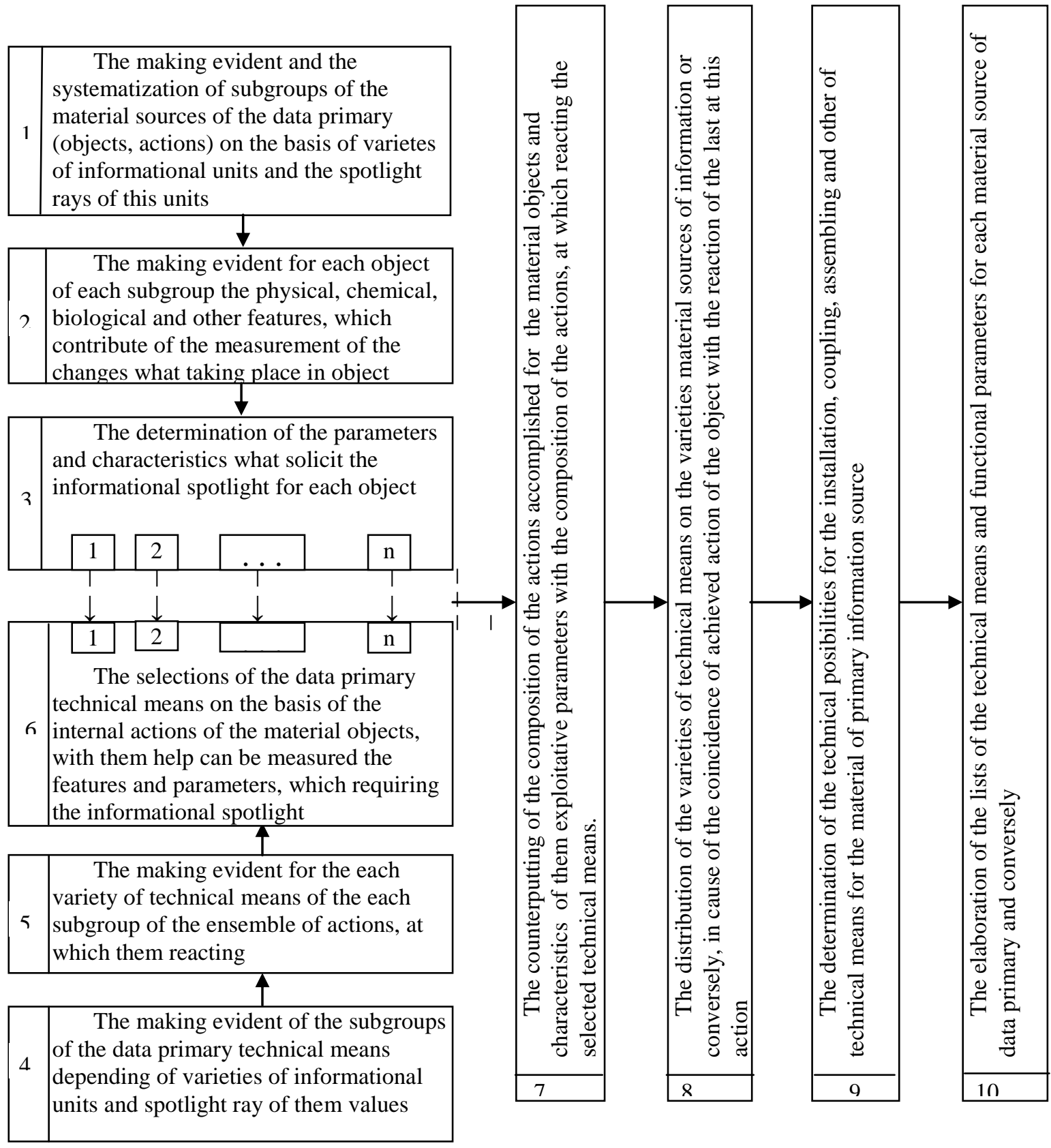

Fig. 1. The scheme of the composition and succession of effecting of the works of stages of the selection of data primary informatics technical means. 
The possible size of the temporary period for obtained and proceeding the informational volume itself determining in next succession :

1) firstly itself determining the temporary interval between the moment of finishing of the material event (it control moment) and the moment of utilization the result information above it:

$T_{p}=M_{\text {u.r. }}-M_{\text {f.e. }} ;$ where :

$M_{\text {u.r. }}$ - the moment of the utilization of result information; $M_{\text {f.e. }}-$ the moment of the finishing of the event.

2) the moment of the utilization of result information so that determining in acordance with the nexts formula :

a) in cause of concomitantly achieveing the all complex of the actions of influence about the leaded object :

$M_{\text {u.r. }}=M_{\text {i.o. }}-V_{\text {t.m. }}$; where : (3)

$M_{i . o}$ - the moment of the influence about the leaded object ; $V_{t . m}$ - the volume of the time alloted for effecting of the must long action at all complex of the actions.

b) in cause, when the actions are effected in mode succesive :

$M_{u . r .}=M_{i . o}-\sum_{i=1}^{n}\left[t_{m i}\right]$;

where :

$t_{m i}$ - the volume of the necessary time of achieving each action $i$, which

influencing the evolution of the leaded object (process) ; $i=\overline{1, n}$ - the composition of the actions weaks about the object.

The graphics interpretation of determination of the time interval necessary for obtained and processing the initial information on the basis of the both variants is presented in figure 2 [1, 313 - 316]. In these schemes $M_{\text {s.c. }} \cdot M_{\text {f.e. }}, M_{\text {o.i. }}$ signified respectivelly the moments of the apearence (creation) of the control situation $\left(M_{\text {s.c. }}\right)$, finished the material event $\left(M_{\text {f.e. }}\right)$ and obtained the initial information $\left(M_{o . i .}\right) ; V_{t}^{\text {s.c. }}, V_{t}^{\text {f.e. }}, V_{t}^{\text {p.r. }}$ - the volumes of the time (the temporary intervals) between the moment of the utilization the results information $\left(M_{\text {u.r. }}\right)$ and respectivelly of the moments of creation the control situation $\left(V_{t}^{\text {s.c. }}\right)$, of finish the material event
( $V_{t}^{\text {f.e. }}$ ) and processing of the obtained initial data $\left(V_{t}^{p r}\right) ; M_{\text {pr.o. }}{ }^{\text {fin }}$ - the moment of the finish of the material precedent and initiation of the succedent process ; $M_{p r .1}$ fin - have the same signification, $M_{p r .2}{ }^{f i n}$ - the finish of the further process a.s.o.; $V_{\text {t.pr. }}$ fin $^{\text {fin }} V_{\text {t.pr. }}$ fin $^{\text {fin }}$ the temporary intervals respectivelly of the material processes 1 and 2 . The other signification being explained in previously formula.

After the determination the size of the temporary interval of obtained of primary data may be established the same necessary interval for transmission of these data on the considerable distance towards of the places them utilization. Disposing of the such two intervals (obtained and transmission of the data primary) itself making the conditions for determination the necessary volume of time for the processing these data. In this goal firstly itself determining the total (general) volume of time and as after this to substract the sum of these two intervals [1, 320 - 325]: Tgen $=$ Text. + Treg. + Tpr. + Ttr';(5) Tpr=Tgen $-($ Text.+ Treg. + Tpr. + Ttr' $) ;(6)$ where: Tgen - the total volume of the necessary time for the obtaining and processing primary (initial) data; Text - the time of the extraction of the values of the data primary; Treg - time of the registering of the primary data; Ttr - the time of the transmission the data primary at the places of them processing; Tpr. - the time of the processing of proposed data primary; Ttr' the time of the transmission the data results at the places of them utilization.

The temporal interval between the moment of the utilization of the result information and the moment of the obtained of the values of the primary (initial) data forming the remaining time for the informational, structural and of the calculus processing. In his turn, such period may be segmented in followings three terms - of introducted $\left(t_{\text {intr }}\right)$, of processing of the introducted data $\left(t_{p r}\right)$ and of the concluding (recording) the results information $\left(t_{\text {extr }}\right)$ :

$$
T_{p r}=t_{\text {intr. }}+t_{p r .}+t_{\text {extr. }}
$$

Once with the calculation the sizes of the temporary periods and the volumes of the 
submisivelly introducting and displaying data, data emergence, of the number of the processing procedures and operations can be calculated the speeds of the functioning of each device of the technical means. That is way all the formula of calculation of the speeds in cause in them dominator containing the sizes of the temporal intervals:

$$
\begin{aligned}
& V_{\text {intr }}=I_{\text {intr }}: t_{\text {intr }} ; V_{\text {ies }}=I_{\text {ies }}: t_{\text {extr }} ;(8) \\
& V_{p r}=\left(N_{\text {inf }}+N_{\text {str }}+N_{\text {oper }}\right) / t_{p r} ;(9)
\end{aligned}
$$

where: $V_{\text {intr }}$ - the speed for data introduction; $I_{\text {intr }}$ - the volume of the introducting data; $t_{\text {intr }}$ - the calculated time data introduction of the; $V_{\text {ies }}$ - the speed of the extraction (recording, posting) of the data emergence; $V_{p r}$ - the speed of data processing ; $N_{i n f}, N_{s t r}, N_{\text {oper }}$ - respectively the numbers of the informational, structural procedures and of calculus operations.

a) the concomitantly (parallel) effecting of the measures of all complex of the actions above leaded object (process) :

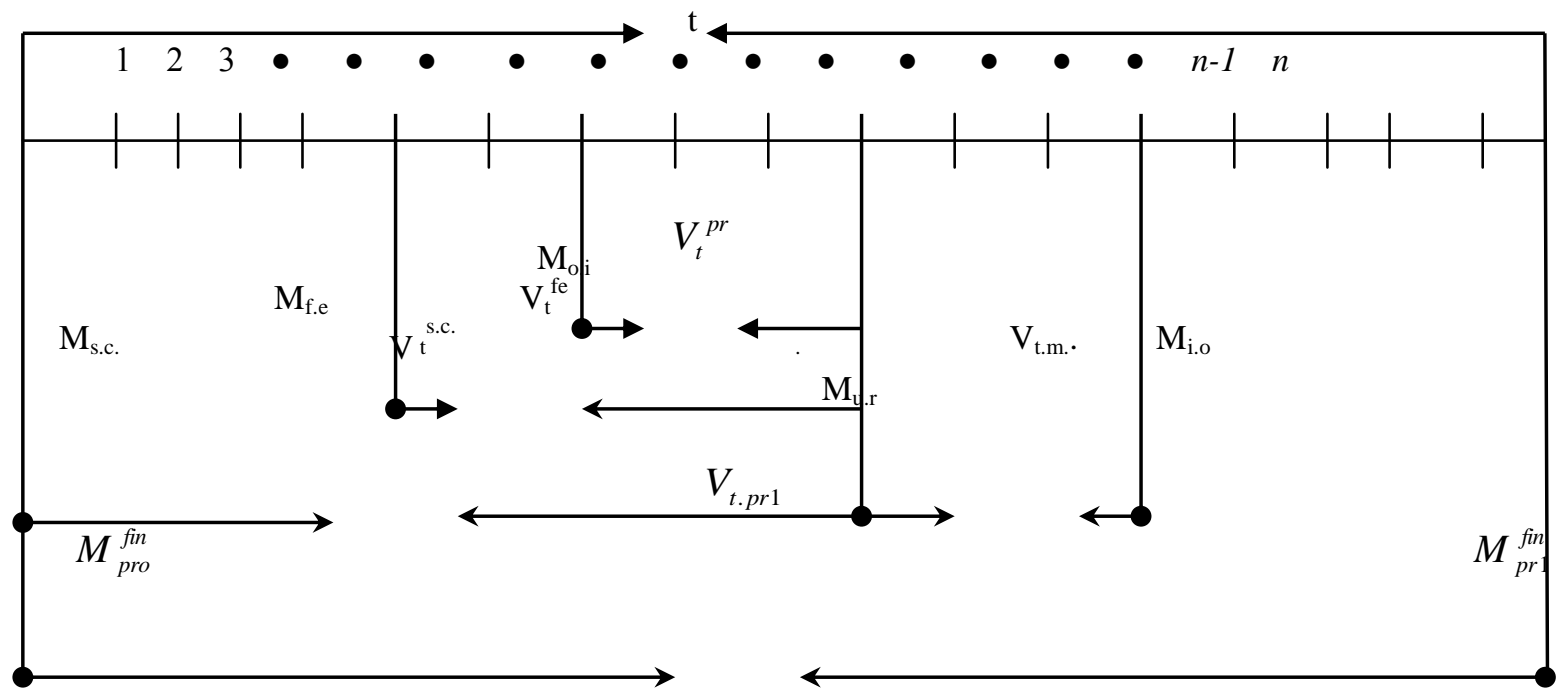

b) the gradually (succesivally) efectuation of measures of all complex of the actions above leadership object (process) :

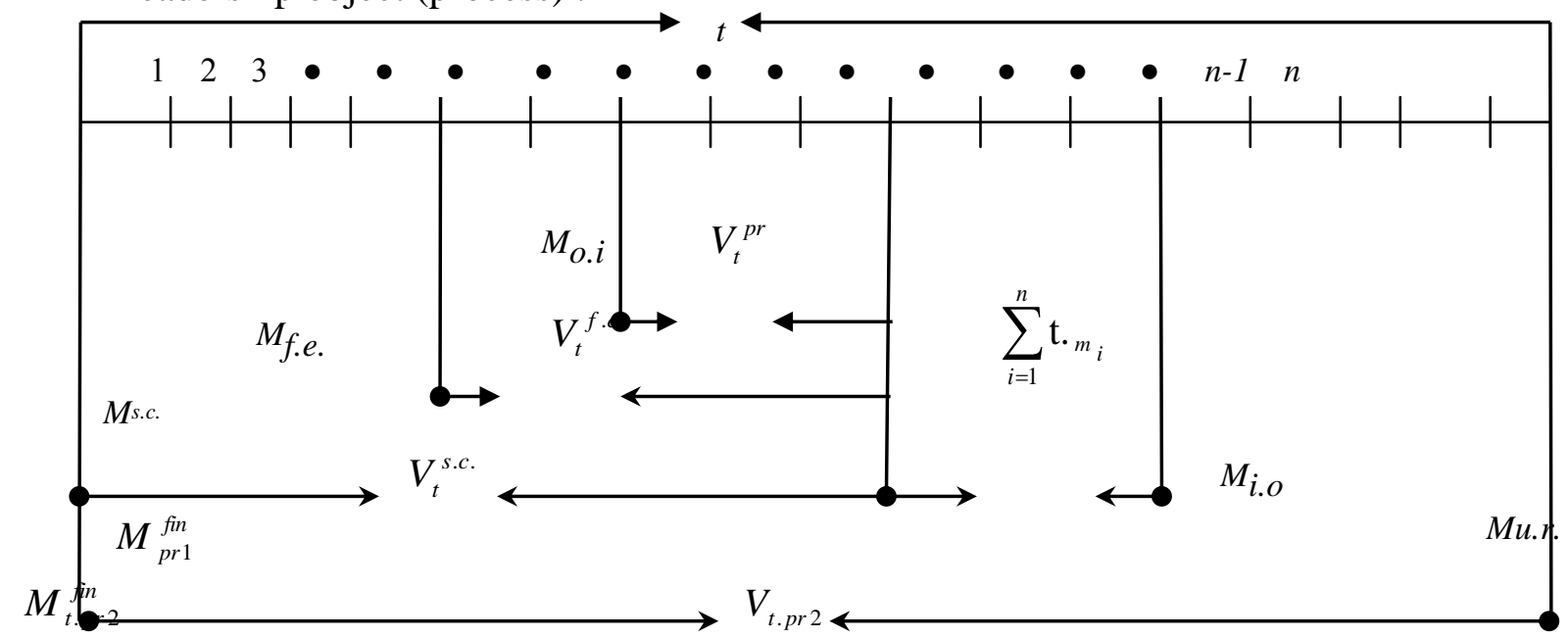

Fig. 2. The graphics interpretation of the process of determination of the size of necessary time interval for obtained of the data initial values and them processing in causes of the two possible variants of effecing of the measures above leaded object (process).

The necessary volume of the memory space for the data keeping $\left(I_{t o t}\right)$ depending of the volums of data introducting $\left(I_{\text {intr }}\right)$, the applied programs $\left(I_{\text {prog }}\right)$ and the volums of the data constants $\left(I_{\text {const }}\right)$ and data rezults $\left(I_{\text {rez }}\right): I_{\text {tot }}=I_{\text {intr }}+I_{\text {prog }}+I_{\text {const }}+I_{\text {rez. }} \quad$ (10) 
Anticipated these calculation itself determining the class of electronic personal computers (E.P.C.). In this goal are calculated and applied the coefficients of the massiveness $\left(K_{m}\right)$ and of the complexity $\left(K_{c p}\right)$ in interconnection of them values, concordant with table 4 as well and, for exemple, those of interconnection, regularity of the values of information entities, etc [1,322-325;2,123-132;3,56-59]

$[1,322-$

325;2,122-132;6,104-106].

Table 4. The selection of the class of personal computers in dependence of the combination of values of the $K_{m}$ and $K_{c p}$

\begin{tabular}{|c|c|c|}
\hline$K_{c p} \backslash K_{m}$ & $\leq 500$ & $>500$ \\
\hline$\leq 10$ & P.C. & P.C. $^{m}$ \\
\hline$>10$ & P.C. $^{a}$ & P.C. \\
\hline
\end{tabular}

In the table P.C.' signifing the computers with the reduced memory volume and the processor with the small speed, P.C. ${ }^{m}-$ the P.C. with the middle such potential and size memory volume; P.C. ${ }^{a}$ - the analogical personal computers and P.C. ${ }^{s}-$ the P.C. of significantly informatics potential.

\section{F. The Selection of the Other Essential Informatics Resources [1, 326 - 368]}

Among other fundamental, which ensuring the working of the E.Ic.S., itself enumering the mathematical, programed, oragnizationaltechnological and social-economic resources. On the conceptual level the selection of the mathematical resources [1,326-339;2,324$336]$ is conditioned of the nexts factors :

1) the exactness of the making evident of the problems composition ;

2) the profoundness of knowledge functional sens of them content ;

3 ) the precisly of the formalization of content ;

4) the maximum concretly guidance of them properties.

The enumerated factors are considered as such the criteria of the selection examined resources. The confrontation of the content, specific features, properties and the evolution of solving process with the description capacities of the resources contributing of the adequate selection.

Further on the basis of such selected resources oneself elaborating the concrete algorithms of the solutions each problem.

In his turn, the elaborated algorithms constitute the basis of the elaboration of programmed resources. That is why the quality of lasts is decisive influenced of the quality the firstly.

Of increased what some mathematical resources (models) in majority are selected, but other (algorithms) are elaborated [ 1, 340-346; 2, 337-342].

Similar and one part of the programmed resources are selected (applied programme packages, operating systems, programme environment), while other part of this resources (applied programme) are elaborated.

The selection of these resources itself producing after selecting of the technical, informational, mathematical and internal technological resources [1,346-359;2,363376]. On that account such procedure is necessary so that taking place with consideration of the specific features and interconnections at of each these components of the E.I.. S., which influencing qualitative (compositional) and quantitative (the volume, the number of the instructions, a.s.o.) the programmed resources. That is why such selections itself reling on them concret specific and characteristics. Among they of decisive value are maximum informational volume of problem, the necessary speed of data processing and concluding, the cathegory of the data structure, the modality of them organizing, the scheme of the internal technology of solving problem, a.s.o. In conclusion, it's necessary to take in account the nexts fundamental principles and particularities of the process of selection of such resources:

1) the specific nature of real applied domain showing the necessity of the selection the systemical and standardized applied programmed resources, whill the original applied programmed resources are 
elaborated, but the standardized are subding of modification ;

2) the programmed resources are must to be selected on the basis of the results of the estimation of another informatics resources, with taking in consideration of the specific and degree of influence of each at them ;

3) at the basis of the selection of all informatics resources must so that standing the values of the parameters and characteristics of informational resources, therefore them constituting the understructure of the lasts ;

4) the selection of the programmed resources must to being effected in complex mode, with taking in account of the specific of each them categories and of as posibble rational modalities of solving of problems ;

5) the apte joining of the fuctional specialization with the universality of the programmed resources ;

6) the rational elaboration and best application must so that oneself effected with help of mathematical apparatus of mini-maxe type ;

7) the reduction at the minimum of the period and the consumptions for the accomodation of the applied satandardized programmed resources at the informational reality ;

8) the iterative character of the process of selection, imposing permanently applieding the miscellaneous news methods of the analysis, comparings and returns at the allready selected informatics resources ;

9) the application of the modulation, passportization and commercialization of programmed resources, inclusively and of any body informatics resources both at the elaborative and at the working stage of the E.Ic.S.

On the route of the selection of the organizational-technological resources it's necessary to take in account and to based on the nexts conceptual principles:

1) the determination of the composition of the external and internal types constituents ;

2) making in evident of the each type of structural units;
3) the distinction of the varietes of such units, which solicite or not the implication of the subject in technological operations ;

4) the defining of the succesion of emplacement of organizational constituents in the process of them working ;

5) the throughly determination of the composition of constituents, with the selection of the more rational and efficient interconnections and interactions, which ensuring the preliminary established working ;

6) the elaboration, examination, analysis and estimation of the varieties of the schemes, definitization the more optimal (best) of the spacial emplacement of the organizational components and of them working in the stipulated temporary regime ;

7) making in evidence, analysis and estimation of the possible methods and proceedings of achievement of them regards the organization and functioning of organizational-technological resources ;

8) the determination of the composition and the necessary volumes of economic resources for ensurance the utilization of this components ;

At once the functional and ergonomics level of the informatics technique has contributed at the creation of such organizational informatics ways (units), how is the informatic post for the activity of the specialist (I.P.A.S.), the system of the

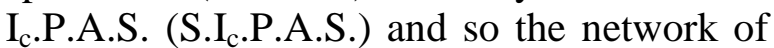
such posts (N.I.P.A.S.), which, in them turn, can be individually or collectively $[1,356-$ 359;2,343-362].

From any point of view (organisational, functional, social, economic, ergonomic) until the informatics network is considered the most succesful way of informatics achievement of informational processes.

Usually, in the composition of the social economics resources [1,359-368] itself include the juridical, normative, administrative and of the psyhological character. In its turn, them are of the general and individual order. The lasts (individuals) are considered the ergonomics and so that 
refering at the creation of favorable conditions for job.

Unlike of other resources, the selection of the juridical not requires the involvement of some calculations, various methods and applied instruments in this domain. Here, of the basic are exactness and adequating of application of the legislative and normative documents in concret situation, them precisely correspondance with reals medium and event, the formulation and taking of the decisions in concordance with required precision. As concerns of the administrative resources, them oneself refering more at the concluding appearence and bringing of knowledge of the executors the juridical, normative documents of the general ordre, which are the attitude both given of social medium of existence and evolution, the and of the given of the medium of professional activity.

Concerning ergonomical - psyhological resources, here until for them selection itself suggesting the application of the universal criteria, characteristics for any domain, while ergonomic resources is necessary to the spread and adaptation at the reality.

\section{Conclusions}

1. The necessity of the selection of informatics resources starting from them domain of application, is founded for the logic of scientific approach and the careful management raison.

2. Such selection contributing at the prolongation of the working period of informatics components.

3. Such requiring the concept of starting at the informational domain towards informatics resources.
4. Anticipated of the selection itself soliciting the certain preparatory works,

5. In accordance with the cleared up concept so that imposing the next succession of selection of informatics components: primary - the methods and procedees of organizing, structuring and transformation

of informational resources, after - the technical means and in them basis - the other resources in the next tidiness : mathematical, programmed,organizational, technological, economic, social, a.s.o.

6. It's necessary for each cathegory of these resources to elaborate or making in evident and of applied the new collections of criteria for them selection.

7. It imposing the accomplishing of the such selection in complex, because the existent informatics components are various, the decisive remaining the informational and technical resources.

\section{References}

[1] T. Leahu Organizarea, structurarea şi transformarea informaţiilor sistemului managerial economic . Monografie. Chişinău, C.E.P. USM, 2009, 431p.

[2] T. Leahu, L. Hâncu Bazele sistemelor informatice economice. Chişinău, C.E.P. USM, 2005, 388 p..

[3] T.Şt. Leahu Despre o metodă de determinare a valorilor parametrilor cantitativi ai informatiilor economice în baza algoritmilor matematici. Materialele Conferinţei internaţionale, vol.I. Chişinău, 2004 ASEM, pp.56-59.

[4] F.S. Leahu. The economic information: organizing, structuring and transformation. Chisinev, 1990, 221 p.(rus).

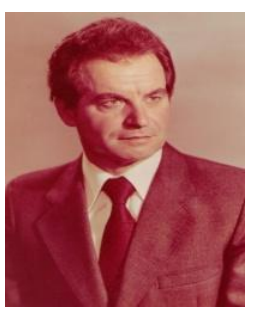

Tudor LEAHU has graduated the Faculty of Economics of State University of Moldova in 1960. He holds a PhD diploma in Economics from 1966 and he had gone through all didactic positions since 1966 vhen he joined the staff of the Chisinau Politechnic Institute (at the present - Technic University of Moldova), teaching assistent in 1966, senior lecturer in 1968, and assistent professor in 1970. Currently he is the Department Head of Economic Informatics Systems of Faculty of Accounting and Economic Informatics of 
aricles, thesis in the domain of elaboration, implementation and working of the economic informatics systems (E.Ic.S.), economic informational systems and data structures, informational and informatics technologies, the economics, protection and efficiency E.Ic.S. His work focuses on the organization, structuration and working the information of the economic managerial systems. 